\title{
Glass/epoxy fiber orientation effects on translaminar fracture toughness under Mixed mode(I/II) load using FPB specimen
}

\author{
Abilash Desai \\ Department of Mechanical Engineering, SDMCET, Dharwad, Karnataka, India \\ abilashdesai@gmail.com \\ C. M. Sharanaprabhu \\ Department of Mechanical Engineering, PESITM, Shivamogga, Karnataka, India \\ cmsharanaprabbu@rediffmail.com \\ S. K. Kudari \\ Department of Mechanical Engineering, CVR College of Engineering, Hyderabad, Telangana, India \\ s.kudari@rediffmail.com
}

\begin{abstract}
To study glass/epoxy fiber orientation effects on translaminar fracture toughness under Mixed mode(I/II) load using asymmetric Four Point Bend specimen. Fracture toughness values for different fiber-oriented glass/epoxy laminates under Mixed modes are compared with unidirectional glass/epoxy laminates. Specimens were fabricated using hand layup technique with $(0 / 45)^{\circ}$ and $(0 / 90)^{\circ}$ fiber oriented glass fiber. The experimental study was conducted for 6 crack positions varying from $\mathrm{s} / \mathrm{d}=0$ (Mode-II) to 1(Mode-1) with an increment of 0.2 for Four Point Bend specimen. The specimens were tested under universal testing machine to obtain peak loads and further evaluate fracture toughness. The experimental test results show fracture toughness can be increased by orienting the fiber in the laminate. Fracture toughness is highly dominating for $(0 / 90)^{\circ}$ fiber-oriented laminates compared to $0^{\circ}$ and $(0 / 45)^{\circ}$ glass/epoxy laminates.
\end{abstract}

\section{OPEN ACCESS}

Citation: Desai, A., Sharanaprabhu, C.M. Kudari, S.K., Glass/epoxy fiber orientation effects on translaminar fracture toughness under Mixed mode(I/II) load using FPB specimen, Frattura ed Integrità Strutturale, 53 (2020) $426-433$.

Received: 22.04 .2020

Accepted: 25.05.2020

Published: 01.07.2020

Copyright: (C) 2020 This is an open access article under the terms of the CC-BY 4.0, which permits unrestricted use, distribution, and reproduction in any medium, provided the original author and source are credited.

KEYwORDS. Asymmetric Four Point Bend; Stress Intensity Factor; Mixed mode I/II.

\section{INTRODUCTION}

$\mathrm{F}$ racture mechanics role in providing engineers and researchers with vital informations for designing and prediction of crack initiation and orientation with its propagation path under Mixed-mode loading is desirable for life prediction of engineering materials [1,2]. Major failure modes revealed that laminated composite undergoes interlaminar, intralaminar and translaminar fracture. For translaminar fracture, very limited research has been carried out. 
Hence for glass/epoxy polymer composites used in aerospace application comes under failure by Mixed mode loading under translaminar fracture. Hence, experimental investigation is necessary for glass/epoxy composites under Mixedmode loading. He and Hutchinson [2] provided accurate results for the stress intensity factors for the asymmetric Four Point Bend (FPB) specimen with an edge crack. A basic solution for an infinitely long specimen loaded by a constant shear force and a linear moment distribution provides the reference on which the finite geometry solution is based. This note was prompted by a comparison of existing numerical solutions for the crack specimen known as the asymmetric Four Point Bend (FPB) specimen. The specimen has distinct advantages for Mixed mode testing, including the determination of Mixed mode fatigue crack thresholds [3]. Reeder presented an investigation for Mixed mode bending test which comprises both Mode-I and Mode-II loading simultaneously using a Mixed mode bending apparatus [4]. Kenane showed delamination fatigue-crack growth experiments have been carried out on unidirectional glass/epoxy laminates using different Mixed mode loadings [5]. Sham Prasad illustrated the interlaminar fracture toughness by Mixed mode using Mixed mode bending tests for polymer-matrix composites [6]. Rikards showed interlaminar fracture toughness for glass fiber reinforced composite was found by testing for Mode-I to Mixed mode then to Mode-II by using a compact tension shear (CTS) specimen and finding critical energy release rate [7]. Laffan showed translaminar fracture toughness measurement can be done in fiber reinforced polymers [8]. Swolfs [9] showed the importance of translaminar fracture toughness for penetration impact behavior of woven carbon/glass hybrid composites. Experimental work was carried out on unidirectional glass/epoxy laminates using FPB specimen and fracture toughness was calculated in our previous work [10]. Orientation of fiber in laminates is important parameter which will affect fracture toughness. Comparing different fiber-oriented laminates was done for Compact Tension Shear and Mixed mode Bending specimens by earlier researchers $[11,12]$. Thus, in the present investigation an effort is made to study translaminar fracture toughness for various fiberoriented glass/epoxy laminates in a Four Point Bend specimen. Experimentation is done for $(0 / 45)^{\circ}$ and $(0 / 90)^{\circ}$ fiber oriented glass/epoxy laminates and is compared with $0^{\circ}$ fiber oriented glass/epoxy laminates in terms of fracture toughness from earlier research[10].

\section{EXPERIMENTATION}

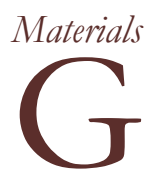

lass-epoxy reinforced polymers are type of laminated composites, which are becoming increasingly popular for various structural applications in the aerospace, automotive and other industrial sectors. The present investigation has been carried out with epoxy resin (Lapox L12) at a room temperature with a curing hardener (H6). All these polymer products were supplied by Atul Limited, Polymer Division (Gujarat, India). The unidirectional glass fiber of $220 \mathrm{gsm}$ having thickness $0.25 \mathrm{~mm}$ was supplied from Marktech Composites, Bangalore, India.

\section{Fabrication of composite}

The aim of the test is to determine the fracture toughness of glass/epoxy composite material with different fiber orientation. To prepare the specimens by hand layup method, 36 layers of glass fiber having $0.25 \mathrm{~mm}$ thickness with 320 $\mathrm{mm}$ length and $190 \mathrm{~mm}$ width were put together with epoxy and hardener to form a block with dimension of $320 * 190 * 9$ $\mathrm{mm}$ for fracture test. Later specimen was cut with dimension of $130^{*} 18^{*} 9 \mathrm{~mm}$. For $(0 / 45)^{\circ}$ laminate, alternate layers of $0^{\circ}$ and $45^{\circ}$ oriented fiber direction were arranged with same dimensions. Fig. 1 (a) shows laminate obtained in $(0 / 45)^{\circ}$ manner. In the same manner to achieve $(0 / 90)^{\circ}$ laminate, alternate layers of $0^{\circ}$ and $90^{\circ}$ oriented fiber direction were arranged with same dimensions. Fig. 1 (b) shows laminate obtained in $(0 / 90)^{\circ}$ manner.

\section{Fracture test}

Mixed mode (I/II) Fracture toughness test for glass-epoxy composite was carried out as per He and Hutchinson [3]. Mixed-mode (I/II) fracture tests were conducted on FPB specimens with a thickness of $9 \mathrm{~mm}(B / W=0.5)$ for both $(0 / 45)^{\circ}$ and $(0 / 90)^{\circ}$ fiber oriented glass/epoxy laminates. The initial crack of $9 \mathrm{~mm}(a / W=0.5)$ is carefully introduced in specimen using a saw cutter of thickness $0.5 \mathrm{~mm}$. The loadings on the specimen used are similar to the one used in the earlier work [13]. Fig. 2 illustrates the major dimensions of the samples used in the tests and Fig. 3 shows Mixed mode testing fixture for accommodating all the Mixed mode distances for FPB specimens from pure Mode-I to pure Mode-II. In this test method, a notched specimen was loaded in compression that has been initially cracked. Specimens prepared were loaded on a computer controlled Universal Testing Machine. The specimens were loaded by fixture which were designed and fabricated using MS steel to perform the fracture test for Mode-I and Mode-II. The tests were closely monitored and conducted at room temperature, since it is difficult to detect the first point of damage in laminated 
composites. In order to overcome such difficulties, the applied loads are recorded. Using recorded values of peak load, the fracture toughness $K_{I C}$ and $K_{I I C}$ will be calculated. The magnitudes of $K_{I C}$ and $K_{I I C}$ have been calculated by analytical formulations given in Eqns. (1) and (2) [3].
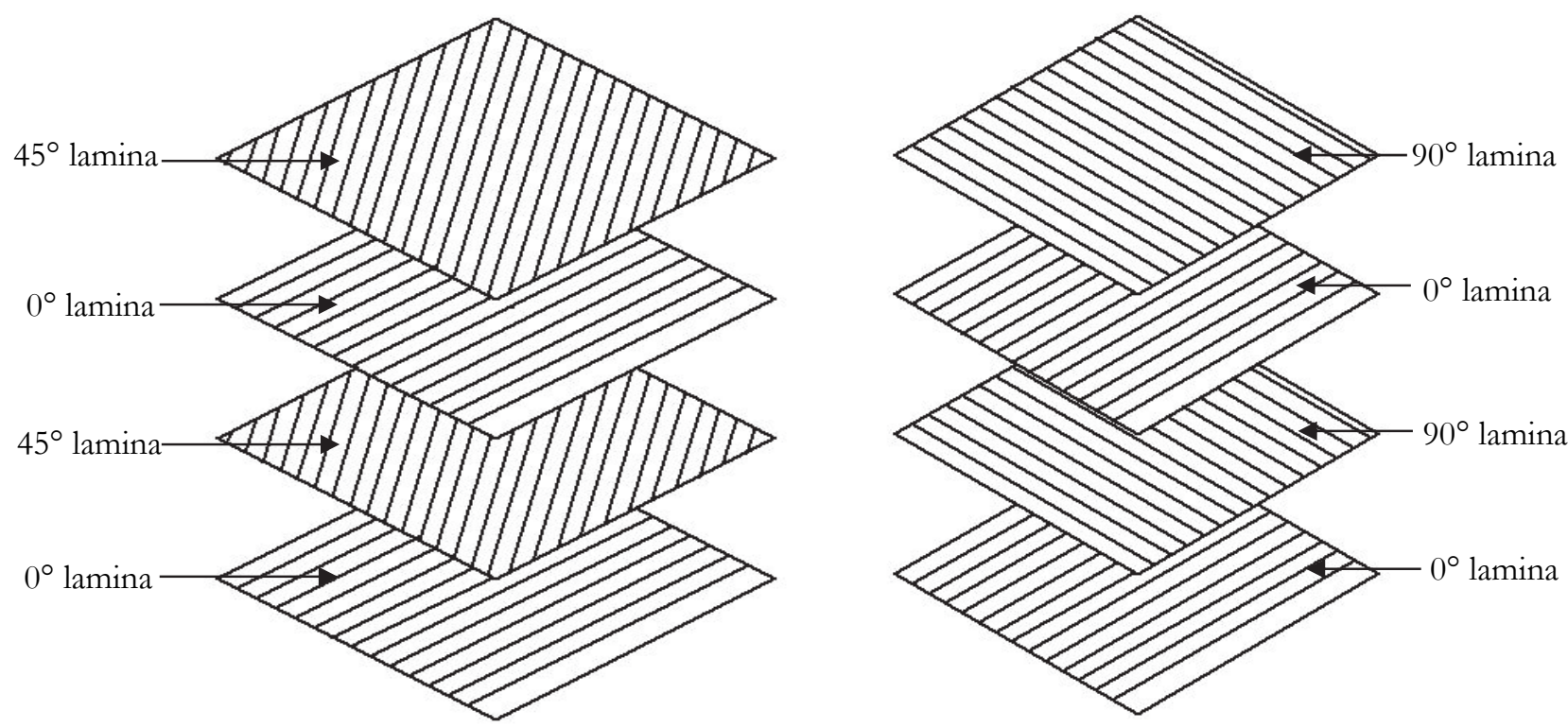

Figure 1: fiber directions of glass laminate obtained in $(0 / 45)^{\circ}$ and $(0 / 90)^{\circ}$ respectively

The analytical formulations of $K_{I}$ and $K_{I I}$ (He and Hutchinson) [3] are as follows:

$$
\begin{aligned}
& K_{I}=\frac{\sigma s Q \sqrt{\pi a}}{W^{2}} F_{I}\left(\frac{a}{W}\right) \\
& K_{I I}=\frac{Q(a / W)^{3 / 2}}{W^{1 / 2}(1-a / W)^{1 / 2}} F_{I I}\left(\frac{a}{W}\right)
\end{aligned}
$$

where

$$
Q=\frac{F(L-d)}{(L+d)}
$$

The functions $\mathrm{F}_{\mathrm{I}}$ and $\mathrm{F}_{\mathrm{II}}$ were defined by Murakami [14], as polynomial functions:

$$
\begin{aligned}
& F_{I}(a / W)=1.122-1.121(a / W)+3.740(a / W)^{2}+3.873(a / W)^{3}-19.05(a / W)^{4}+22.55(a / W)^{5} \\
& \text { for } \quad a / W \leq 0.7 \\
& F_{I I}(a / W)=7.264-9.37(a / W)+2.74(a / W)^{2}+1.87(a / W)^{3}-1.04(a / W)^{4} \\
& \text { for } \quad 0 \leq a / W \leq 1 \\
& K_{\text {eff }}=\sqrt{K_{I}^{2}+K_{I I}^{2}}
\end{aligned}
$$


Here ' $F$ ' is the peak load, ' $t$ ' is the thickness of the specimen and $F_{I}(a / W)$ and $F_{I I}(a / W)$ are the non-dimensional geometrical factors for both pure Mode-I and pure Mode-II. Fracture tests were performed with a universal tensile testing machine under a loading speed of $2 \mathrm{~mm}$ per minute. Tests were conducted three times for each specimen laminates. The critical stress intensity factor $\left(K_{I C} \& K_{I I C}\right)$ value was calculated from this peak load by equations that have been established on specimens of the type described in He and Hutchinson [3].

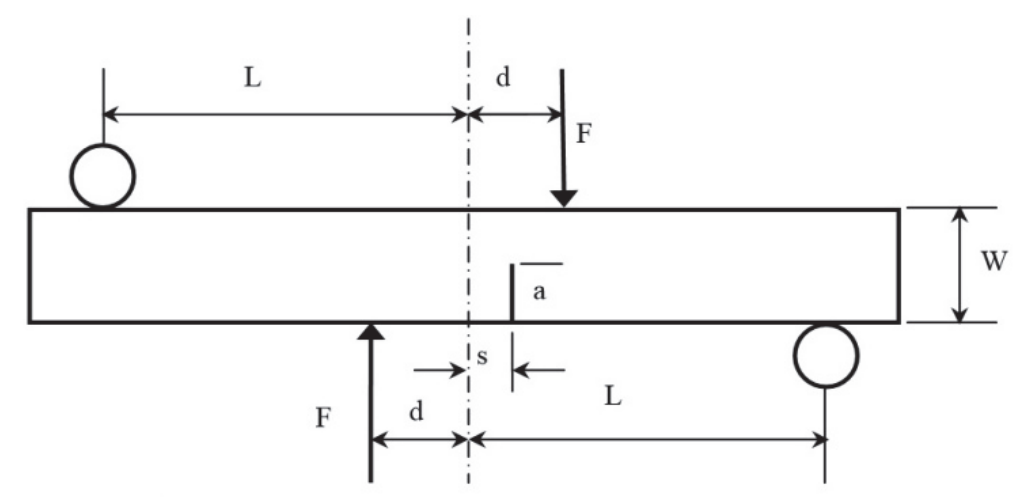

Figure 2: Specimen configuration used in the analyses $W=18 \mathrm{~mm}, d=26 \mathrm{~mm}, \mathrm{~L}=52 \mathrm{~mm}, \mathrm{a}=9 \mathrm{~mm}$.

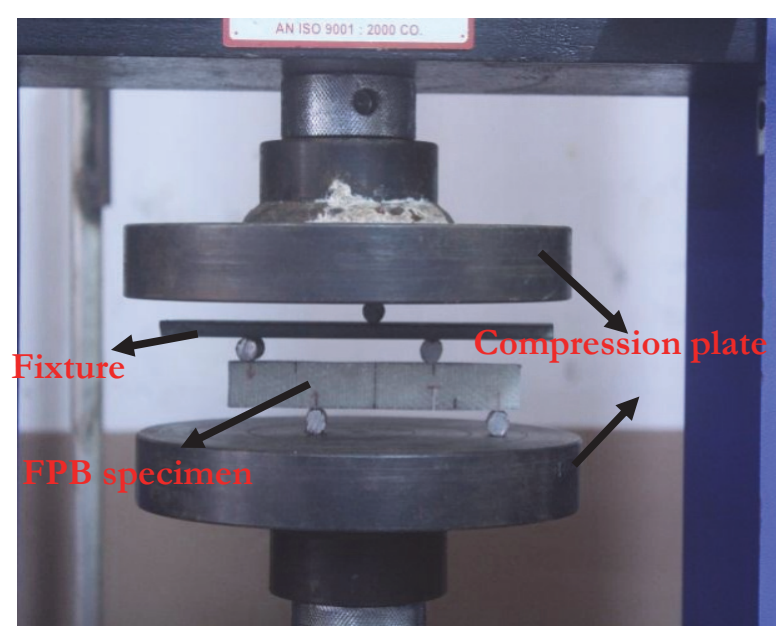

Figure 3: Arrangement of FPB specimen loaded at UTM

\section{RESULTS AND DISCUSSIONS}

\section{Fracture behavior of glass-epoxy polymer composite}

7 he specimen is loaded for 6 different crack positions (i.e. $d / W=1.5$ constant for all the specimens). These 6 cases correspond to the different crack distances from the middle of the specimen by varying the $s / d$ ratios from 0 to 1 by an increment of 0.2. Fracture behavior of laminates for different loading positions in the specimen, showed that the crack in the specimen initiated at the crack tip and then propagated along the fibre/matrix interface. Thus, for loading positions other than $s / d=0$ and $s / d=1$, the cracks propagate under Mixed mode loading conditions. A set of five specimens were prepared for each loading conditions and the peak load experienced by the specimen is computed by the average of best three specimen results. It is observed that the deviation in the load is less than $2.5 \%$. The estimated average load $v$ s. displacement values is plotted in Fig. 4 for $(0 / 45)^{\circ}$ and $(0 / 90)^{\circ}$ fiber oriented glass/epoxy. Load is applied for various $\mathrm{s} / \mathrm{d}$ ratios of the specimen to calculate the stress intensity factor $(K)$. Load displacement curves from the experimental fracture are gathered and from these curves, the peak loads ( $F$ ) at fracture are used to compute critical Mode-I and Mode-II stress intensity factors. Tab. 1 and Tab. 2 gives peak load values and corresponding stress intensity 
factors for corresponding $s / d$ ratios for $(0 / 45)^{\circ}$ and $(0 / 90)^{\circ}$ laminates respectively. The magnitudes of $K_{I C}$ and $K_{I I C}$ have been calculated by analytical formulations given in Eqns. (1) and (2) [3].

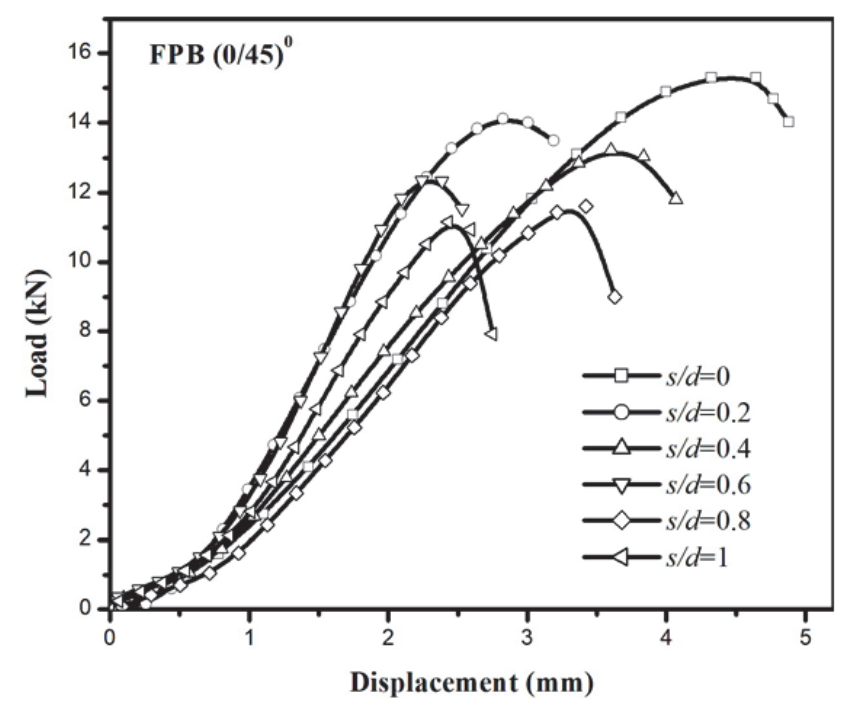

(a)

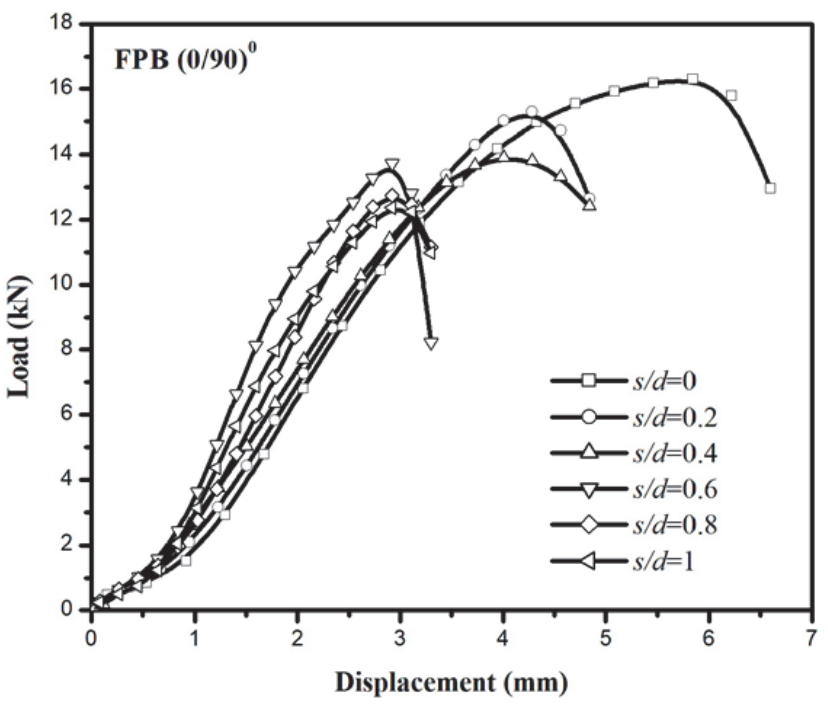

(b)

Figure 4: Load $v$ s. displacement $(0 / 45)^{\circ}$ and $(0 / 90)^{\circ}$ fiber oriented glass/epoxy laminates

\begin{tabular}{ccccc}
\hline$s / d$ & $\begin{array}{c}\text { Average Peak Load } \\
F(\mathrm{~N})\end{array}$ & $\begin{array}{c}K_{I C} \\
\left(\mathrm{MPa}(\mathrm{m})^{1 / 2}\right)\end{array}$ & $\begin{array}{c}K_{\text {IIC }} \\
\left(\mathrm{MPa}(\mathrm{m})^{1 / 2}\right)\end{array}$ & $\begin{array}{c}K_{\text {eff }} \\
\left(\mathrm{MPa}(\mathrm{m})^{1 / 2}\right)\end{array}$ \\
0 & 15000 & 0.00 & 10.66 & 10.66 \\
0.2 & 14250 & 19.14 & 10.13 & 21.65 \\
0.4 & 13320 & 35.77 & 9.47 & 37.00 \\
0.6 & 12690 & 51.12 & 9.02 & 51.91 \\
0.8 & 11930 & 64.08 & 8.48 & 64.64 \\
1 & 11310 & 75.94 & 0.00 & 75.94 \\
\hline
\end{tabular}

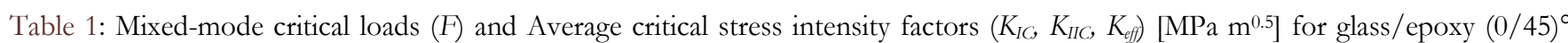
laminate.

\begin{tabular}{ccccc}
\hline$s / d$ & $\begin{array}{c}\text { Average Peak Load } \\
\mathrm{F}(\mathrm{N})\end{array}$ & $\begin{array}{c}K_{I C} \\
\left(\mathrm{MPa}(\mathrm{m})^{1 / 2}\right)\end{array}$ & $\begin{array}{c}K_{\text {IIC }} \\
\left(\mathrm{MPa}(\mathrm{m})^{1 / 2}\right)\end{array}$ & $\begin{array}{c}K_{\text {eff }} \\
\left(\mathrm{MPa}(\mathrm{m})^{1 / 2}\right)\end{array}$ \\
0 & 16320 & 0.00 & 11.60 & 11.60 \\
0.2 & 15420 & 20.71 & 10.96 & 23.43 \\
0.4 & 14380 & 38.62 & 10.22 & 39.95 \\
0.6 & 13650 & 54.99 & 9.70 & 55.84 \\
0.8 & 12880 & 69.18 & 9.15 & 69.79 \\
1 & 12140 & 81.51 & 0.00 & 81.51 \\
\hline
\end{tabular}

Table 2: Mixed-mode critical loads $(F)$ and Average critical stress intensity factors $\left(K_{I C}, K_{I I C}, K_{e f f}\left[\mathrm{MPa} \mathrm{m}^{0.5}\right]_{\text {for }}\right.$ glass/epoxy $(0 / 90)^{\circ}$ laminate. 
Fig. 5 shows $K_{I C}$ vs. $s / d$ for various fiber-oriented laminates. Critical Stress Intensity factors are increasing from pure Mode-II to pure Mode-I. Fig. 6 shows $K_{I I C} v s . s / d$ for various fiber-oriented laminates. Critical Stress Intensity factors are decreasing from pure Mode-II to pure Mode-I. Also, we can observe $(0 / 90)^{\circ}$ fiber oriented laminate is dominant compared to other fiber oriented laminate. Critical stress intensity factor is considered as fracture toughness. The failure under Mixed mode loading i.e. variation of $K_{I I C} v$ s. $K_{I C}$ is depicted in Fig. 7 . This nature of variation of $K_{I I C} v$ s. $K_{I C}$ is in good agreement with the results shown by our earlier experimental work under Mixed mode loading [10]. Fracture toughness value of $(0 / 90)^{\circ}$ fiber oriented laminates are highest among other fiber oriented laminates. Also, $(0 / 90)^{\circ}$ fiber orientation fabrication is simple compared to $(0 / 45)^{\circ}$ fiber orientation. Hence $(0 / 90)^{\circ}$ fiber oriented laminates can be preferred for industrial purpose. Fig. 8 shows $K_{\text {eff }} v$ s. $s / d$ for various fiber-oriented laminates. This figure indicates that, the effective stress intensity factor in Mode-I is more than that of Mode-II which indicates specimen fails earlier in Mode-I compared to Mode-II and Mixed modes.. Also, nature of variation of $K_{\text {eff }} v$ s. $s / d$ is similar to earlier researchers [2]. Fig. 9 shows fracture behavior of laminates at different loading positions from $\mathrm{s} / \mathrm{d}=0$ to 1 . From Fig. 9 we can see that, for $\mathrm{s} / \mathrm{d}=0$, fracture takes in pure Mode-II. For s/d=1, fracture takes place in pure Mode-I. For s/d=0.2, 0.4, 0.6 and 0.8 fracture takes place in Mixed mode. As we have conducted experimentation on specimen using crack perpendicular to fiber direction, the nature of failure will be translaminar. After the experiment crack tip is examined through optical microscope having 100X magnification which reveals fiber breakage as is shown in Fig. 10.

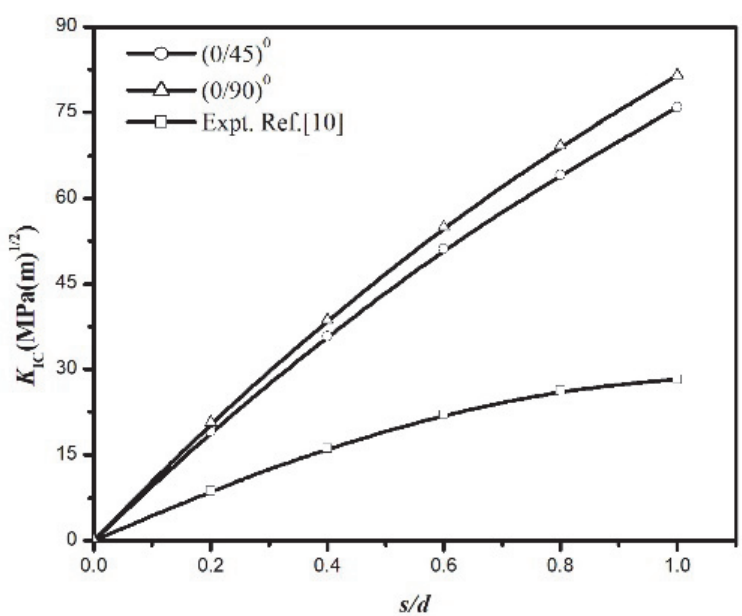

Figure 5: $K_{I C} v$ s. $s / d$

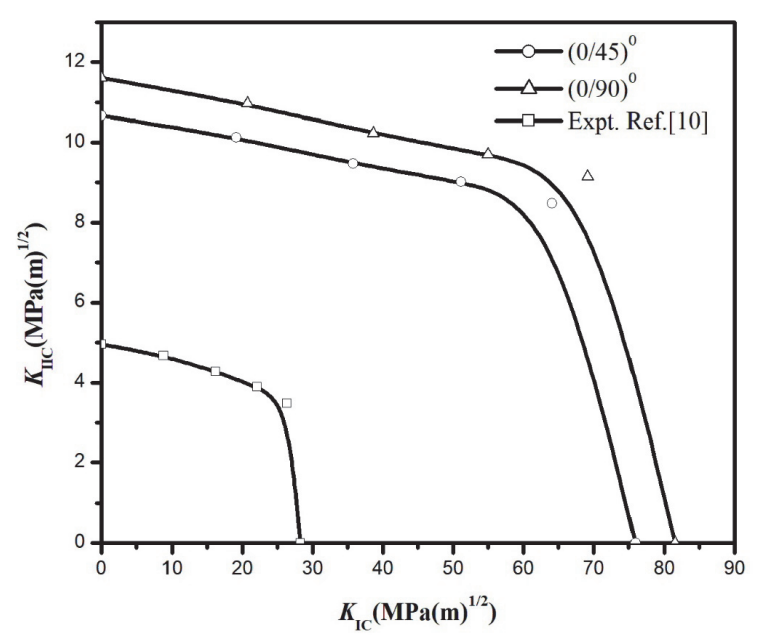

Figure 7: $K_{I I C} v s . K_{I C}$

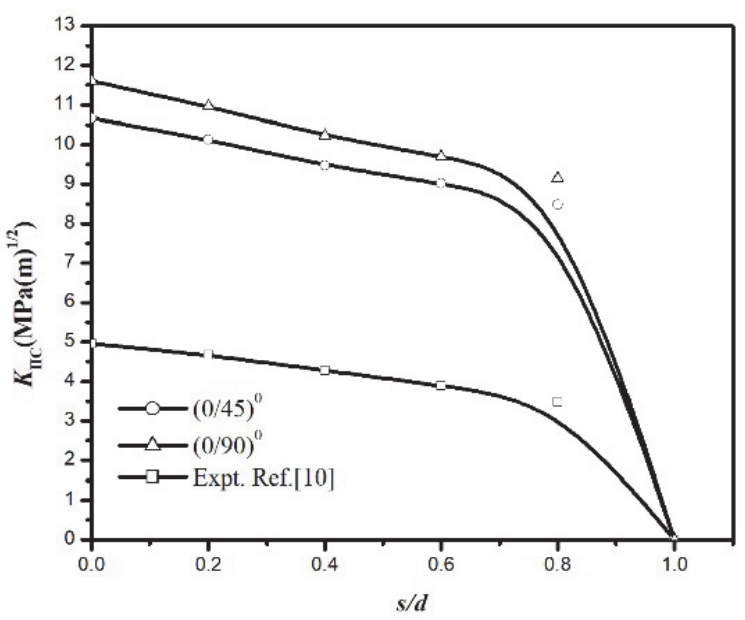

Figure 6: $K_{\text {IIC }} v$ s. $s / d$

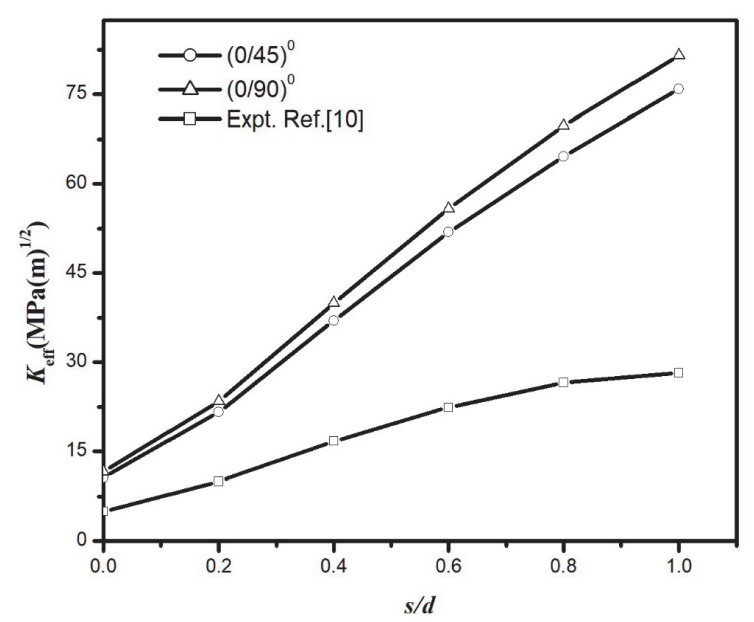

Figure 8: $K_{e f f} v s . s / d$ 


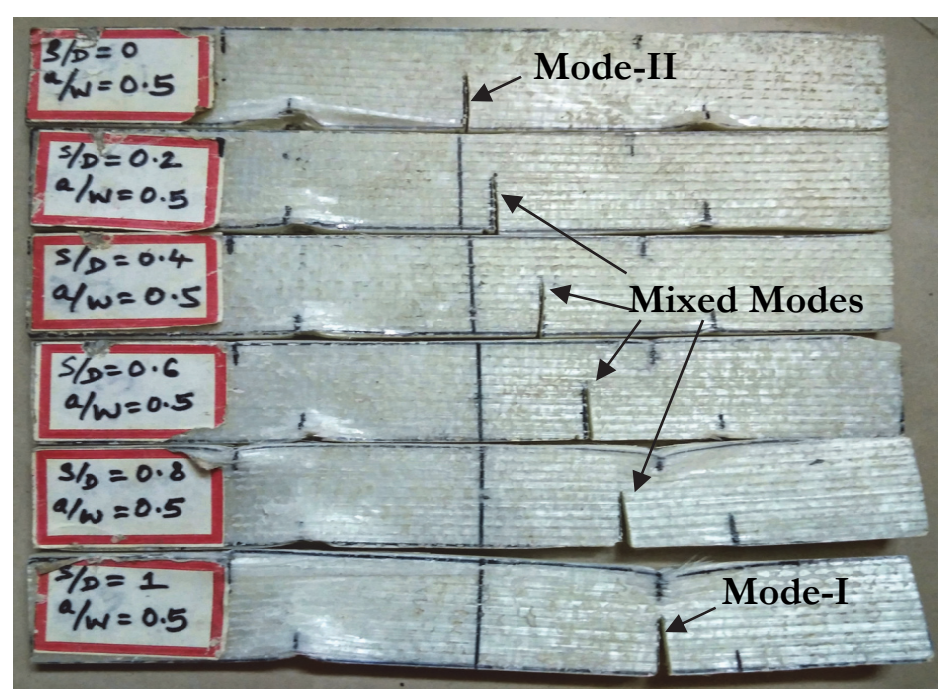

Figure 9: Fracture behavior of laminates at different loading position

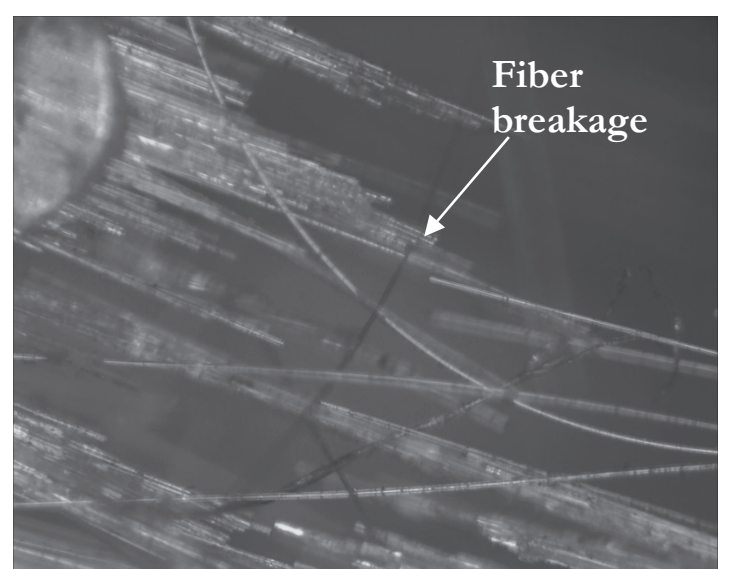

Figure 10: Fiber breakage seen using optical microscope

Mode mixity (Me) is calculated for different s/d ratios for FPB specimen [2] using Eqn. (7). Tab. 3 shows values for mode mixity for $s / d$ ratios.

$$
M_{e}=\left(\frac{2}{\pi}\right) \arctan \left(\frac{K_{I}}{K_{I I}}\right)
$$

\begin{tabular}{cc}
$s / d$ & $\begin{array}{c}\text { Mode-mixity } \\
M_{e}\end{array}$ \\
0 & 0 \\
0.2 & 0.69 \\
0.4 & 0.835 \\
0.6 & 0.888 \\
0.8 & 0.916 \\
1 & 1 \\
\hline
\end{tabular}

Table 3: Mode-mixity values for various s/d ratios

\section{CONCLUSION}

he major conclusions in this investigation is that, the bearing load capacity for unidirectional $(0 / 90)^{\circ}$ fiber oriented laminate is more compared to $0^{\circ}$ and $(0 / 45)^{\circ}$ unidirectional fiber oriented laminate for asymmetric Four Point Bend Mixed mode(I/II) fracture specimen. Consequently, the translaminar fracture toughness for $(0 / 90)^{\circ}$ is more compared to other fiber oriented laminates. In addition, Fabrication process for $(0 / 90)^{\circ}$ fiber oriented laminate using hand layup technique is simple compared to $(0 / 45)^{\circ}$ fiber oriented laminate. Hence, $(0 / 90)^{\circ}$ fiber oriented laminate is preferable for industrial application. 


\section{ACKNOWLEDGMENT}

uthors gratefully acknowledge the experimental facilities provided by the Research Centre, S.D.M. College of
Engineering \& Technology, Dharwad, Karnataka, India and Research Centre, PESITM, Shivamogga, Karnataka,
India.

\section{REFERENCES}

[1] Laffan, M.J., Pinho, S.T., Robinson, P., McMilllan, A.J. (2012). Translaminar fracture toughness testing of composites: A review", Polymer Testing, , pp. 481-489. DOI: 10.1016/j.polymertesting.2012.01.002.

[2] Kudari, S. K., Sharanaprabhu, C.M. (2010). On the relationship between stress intensity factor (K) and minimum plastic zone radius (MPZR) for four-point bend specimen under Mixed mode loading, International Journal of Engineering, Science and Technology, 2(5), pp. 13-22. DOI: 10.4314/ijest.v2i5.60095.

[3] He, M. Y., Hutchinson, J.W. (2000). Asymmetric four-point crack specimen. Journal of Applied Mechanics, 67, pp. 207-209. DOI: $10.1115 / 1.321168$

[4] James, R. R. (1990). Mixed-mode Bending Method for Delamination Testing, AIAA Journal, 28(7), pp. 1270-1276. DOI: $10.2514 / 3.25204$

[5] Kenane, M., Benzeggagh, M. L. (1997). Mixed-mode delamination fracture toughness of unidirectional glass/epoxy composites under fatigue loading, Composites Science and Technology, 57 pp. 597-605. DOI: 10.1016/S0266-3538(97)00021-3

[6] Sham Prasad, M.S., Venkatesh, C.S. and Jayaraju, T.(2011). Experimental methods of determining fracture toughness of fiber reinforced polymer composites under various loading conditions, Journal of Minerals and Materials Characterization \& Engineering 10(13), pp. 1263-1275. DOI: 10.4236/jmmce.2011.1013099

[7] Rikards, R. (1998). Investigation of Mixed mode I/II interlaminar fracture toughness of laminated composites by using a CTS type specimen, Engineering Fracture Mechanics, 61, pp. 325-342. DOI: 10.1016/S0013-7944(98)00068-X.

[8] Laffan, M.J., Pinho, S.T., Robinson, P., McMilllan, A.J. (2011). Translaminar fracture toughness: The critical notch tip radius of $0^{\circ}$ plies in CFRP, Composites Science and Technology, 72, pp. 97-102.

DOI: 10.1016/j.compscitech.2011.10.006

[9] Swolfs, Y., Geboes, Y., Gorabatikh, L., Pinho, S. T. (2017). The importance of translaminar fracture toughness for the penetration impact behaviour of woven carbon/glass hybrid composites, Composites Part A, 103, pp. 1-8. DOI: 10.1016/j.compositesa.2017.09.009

[10] Desai, A., Sharanaprabhu, C.M., Kudari, S.K. (2018). Experimental Investigation on Critical Energy Release Rate for an Asymmetric Four Point Bending, National Conference on advanced research in science, engineering and management, PESITM, Shivamogga pp. 395-398.

[11] Desai, A., Sharanaprabhu, C.M., Kudari, S.K. (2019). Experimental Investigation on the effects of fiber orientation on mixed mode I/II translaminar fracture toughness for glass-epoxy composites, Advances in polymer composites, Mechanics, Characterization and Applications, AIP Conf. Proc.2057, 020010. DOI: 10.1063/1.5085581.

[12] Naghipour, P., Bartsch, M., Chernova, L., Hausmann, J., Voggenreiter, H. (2010). Effect of fiber angle orientation and stacking sequence on mixed mode fracture toughness of carbon fiber reinforced plastics: Numerical and experimental investigations, Materials Science and Engineering A, 527 pp. 509-517. DOI: 10.1016/j.msea.2009.07.069.

[13] Shahani, A.R., Tabatabaei, S.A. (2009). Effect of T-stress on the fracture of a four point bend specimen, Materials and Design, 30, pp. 2630-2635. DOI: 10.1016/j.matdes.2008.10.031

[14] Murakami ,Y. Stress Intensity factors handbook, Pergamon Press, New York (1987) 